\title{
The hypoxic tumour microenvironment
}

\author{
Varvara Petrova ${ }^{1}$, Margherita Annicchiarico-Petruzzelli ${ }^{2}$, Gerry Melino ${ }^{1,3}$ and Ivano Amelio (1)
}

\begin{abstract}
Cancer progression often benefits from the selective conditions present in the tumour microenvironment, such as the presence of cancer-associated fibroblasts (CAFs), deregulated ECM deposition, expanded vascularisation and repression of the immune response. Generation of a hypoxic environment and activation of its main effector, hypoxiainducible factor-1 (HIF-1), are common features of advanced cancers. In addition to the impact on tumour cell biology, the influence that hypoxia exerts on the surrounding cells represents a critical step in the tumorigenic process. Hypoxia indeed enables a number of events in the tumour microenvironment that lead to the expansion of aggressive clones from heterogeneous tumour cells and promote a lethal phenotype. In this article, we review the most relevant findings describing the influence of hypoxia and the contribution of HIF activation on the major components of the tumour microenvironment, and we summarise their role in cancer development and progression.
\end{abstract}

\section{Hypoxia and hypoxia-inducible factors}

The major components of the tumour microenvironment (TME) are blood vessels, lymphatic vessels, fibroblasts, immune cells and chemico-physical components such as the extracellular matrix $(\mathrm{ECM})^{1}$. The functional and physical interaction of these elements with cancer cells determines clinical outcomes. During tumour development and progression, cancer and stromal cells often have restricted access to nutrients and oxygen. Most solid tumours indeed have regions permanently or transiently subjected to hypoxia because of aberrant vascularisation and a poor blood supply ${ }^{2}$. The hypoxic response is mainly ascribed to hypoxia-inducible factors (HIFs). HIF-dependent signalling can promote the adaptation and selection of both cancer and stromal cells to the surrounding conditions, thus promoting changes that favour cancer progression. The HIF family of transcription factors includes HIF1, HIF2 and HIF3. These factors all contain an oxygen-sensitive HIF- $\alpha$ subunit (HIF1- $\alpha$, HIF2- $\alpha$ or HIF3- $\alpha$, respectively), which dimerises with the constitutively expressed HIF1- $\beta$ subunit ${ }^{3}$. HIF1- $\alpha$ and HIF2- $\alpha$ proteins are the best studied among HIF- $\alpha$

\footnotetext{
Correspondence: Ivano Amelio (ia119@le.ac.uk)

${ }^{1}$ Medical Research Council, Toxicology Unit, Leicester University, Hodgkin Building, Lancaster RoadP.O. Box 138, Leicester LE1 9HN, UK

${ }^{2}$ Biochemistry Laboratory, IDI-IRCCS, Rome, Italy

Full list of author information is available at the end of the article
}

subunits. Each of these subunits contains two proline residues (HIF1- $\alpha$ : P402/P564 and HIF2- $\alpha$ : P405/P531), which are hydroxylated in the presence of oxygen by prolyl hydroxylase domain-containing proteins (PHDs). Hydroxylation of the proline residues promotes binding to von Hippel-Lindau tumour suppressor (pVHL), leading to HIF- $\alpha$ ubiquitination and degradation ${ }^{4,5}$. Another factor regulating HIF- $\alpha$ in an oxygen-dependent manner is factor inhibiting HIF1 (FIH1). Asparagine hydroxylation of HIF1- $\alpha$ (and to a lesser extent, of HIF2- $\alpha$ ) driven by FIH1 impedes HIF1 interaction with its cofactors, histone acetylases p300 and CBP, and hence impairs HIF1 transcriptional activity $^{6-8}$. The hypoxic tumour microenvironment (TME) is subjected to HIF-driven transcriptional responses in cancer and stromal cells. In addition, HIF activity switches the cell metabolism into glycolytic mode, increasing glucose consumption and pyruvate, lactate and $\mathrm{H}+$ production. In this review article, we summarise and discuss the influence of hypoxia and HIFs on TME components and how this impacts cancer progression.

\section{Cancer-associated fibroblasts (CAFs)}

It is widely accepted that fibroblasts infiltrating tumour tissue acquire very different features from normal fibroblasts, leading to the definition of CAF. CAFs often represent the major component of tumour stroma, 


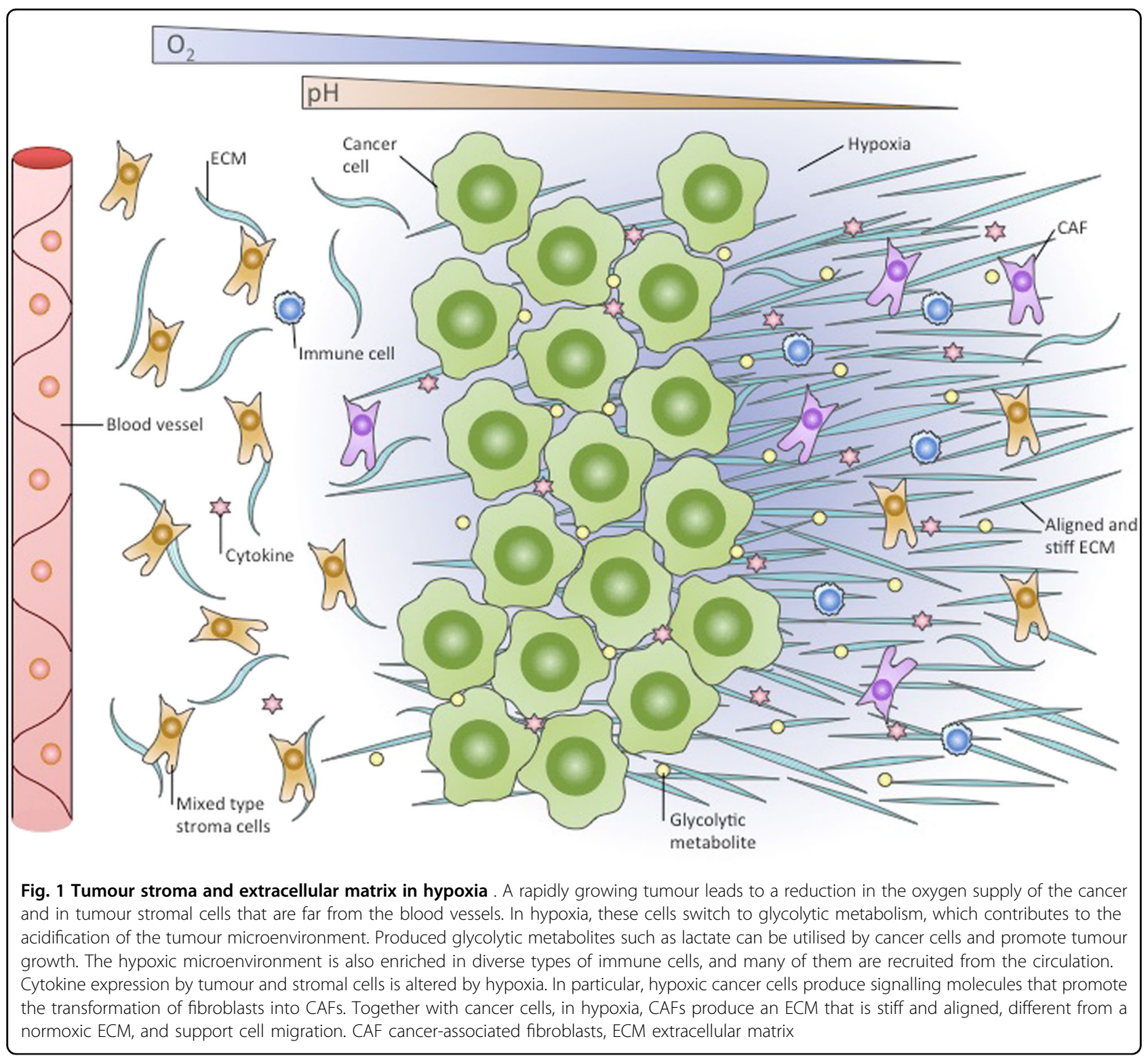

sometimes constituting up to the $80 \%$ of the entire tumour ${ }^{9}$. The population of CAFs can be quite heterogeneous, as several progenitor cell types can be reprogrammed into CAFs. Although most CAFs are considered to arise from resident fibroblasts, bone marrow cells, adipocytes, endothelial cells and epithelial cells can also turn into CAFs ${ }^{10-17}$.

Reciprocal paracrine signalling between murine cancer cells and fibroblasts was described by Olaso et al. Melanoma cells could induce proliferation and expression of CAF marker $\alpha$-SMA in adjacent fibroblasts. These fibroblasts excessively produced glucosaminoglycans and MMP-2, promoting the migration of melanoma cells ${ }^{18}$. Following this initial study, the ability of CAFs to favour tumour progression was shown in a prostate cancer xenograft model when CAFs were co-injected with initiated (tumorigenic) prostatic epithelial cells and promoted their tumorigenic potential, in contrast to co-injection with normal fibroblasts ${ }^{19}$. A study by Bhomwick and Colleagues demonstrated that TGF-beta type II receptor deficiency in mouse fibroblasts led to increased HGF secretion and initiation of tumour formation in adjacent prostate and forestomach epithelium ${ }^{20}$, suggesting one possible mechanism of fibroblast transformation. Other examples of paracrine signalling that is deregulated by CAFs include the secretion of chemokine CXCL12 with subsequent tumour growth facilitation and the expression of intra-cellular and extracellular $\mathrm{Ca} 2+$-binding protein S100A4 with subsequent tumour progression and metastatic spread ${ }^{21,22}$. Except for paracrine signalling, the 
oncogenic functions of CAFs are partially mediated by altered ECM production. In a breast cancer study, ECM deposited by CAFs was organised differently (aligned) than ECM produced by normal fibroblasts and could influence premalignant human mammary epithelial cells, assigning them a mesenchymal phenotype and increasing their tumorigenic and metastatic potential. The mesenchymal phenotype transition in epithelial cells is dependent on the TGF- $\beta$-dependent Smad, Erk, Jun and Rho signalling pathways. As TGF- $\beta$ is stored in the ECM before activation, the function of CAFs in that model could consist of increasing TGF- $\beta$ availability as well as building an ECM framework with a metastasis-promoting spatial structure ${ }^{23-26}$. In addition to the direct effect of CAFs on cancer cells, they can promote angiogenesis via vascular endothelial growth factor-C (VEGF), CXCL12a and FGF-2 factor production and modulate the immune response by inducing macrophage infiltration and tumour-promoting cell polarisation, reducing T-cell infiltration and interfering with natural killer cell function ${ }^{27}$.

Hypoxia can influence both fibroblast reprogramming and tumour-promoting functions (Fig. 1). Oxygen deficiency influences paracrine signalling between cancer cells and fibroblasts. Hypoxia was shown to stimulate cytokine CXCL13 secretion by cancer-associated myofibroblasts in prostate cancer progression ${ }^{28}$. While CAFs secrete chemokine CXCL12, facilitating cancer growth ${ }^{22}$, hypoxia was shown to stimulate CXCR4 (CXCL12 receptor) expression in many cell types, therefore suggesting a feed-forward loop between cancer cells and $\mathrm{CAFs}^{29}$. Hypoxic cancer cells can secrete paracrine signalling molecules, which promote reprogramming of progenitor cells into $\mathrm{CAFs}^{30}$, and HIF1 was shown to regulate some of these signalling molecules, such as TGF$\beta$, bFGF and PDGF- $\mathrm{B}^{31-33}$.

It has been shown that the hypoxia-inducible factor-1 (HIF-1) $\alpha$ level is often upregulated in CAFs. In a model in which CAF formation is stimulated by TGF- $\beta$ and PDGF treatment, the rate of aerobic glycolysis in primary CAFs was increased compared to that in normal fibroblasts, and this effect was associated with HIF- $1 \alpha$ protein stabilisation $^{34,35}$. The lactate produced by highly glycolytic CAFs can be consumed by adjacent cancer cells and lead to induced tumour growth, which suggests a negative outcome of HIF-1 upregulation in fibroblasts ${ }^{34}$. The role of the increase in HIF-1 $\alpha$ levels during CAF formation is still poorly understood, that is, whether it is a driving force for reprogramming or a consequence. Chiavarina and colleagues observed that stable HIF-1 $\alpha$ overexpression endowed fibroblasts with oncogenic functions, as they increased tumour growth after ectopic co-injection with breast cancer cells. The proposed mechanism included HIF-1 $\alpha$-promoted autophagy, mitophagy, and the production of lactate and recyclable nutrients, which could fuel cancer cells and provide them with building blocks $^{36-39}$. However contradicting evidence supports a negative regulatory role for HIF-1a signalling in stromal fibroblast. Kim and Colleagues indeed showed that selective deletion of HIF-1a (or VEGFA) in fibroblast was enhancing tumour growth in murine mammary cancer models ${ }^{40}$. Additionally after $80 \mathrm{~h}$ of hypoxia normal fibroblasts were shown to produce a stiff, aligned matrix, and that this matrix supported the migration of breast cancer cells ${ }^{41}$. Confirming the abovementioned experiments hypoxia was inducing secretion of protumorigenic factors, such as hepatocyte growth factor (HGF), in human fibroblast cell line MRC5 due to HIF-1 activity. Conditioned media from hypoxic MRC5 could promote invasiveness of pancreatic cancer cell line PK8 ${ }^{42}$. Thus several studies have shown gain of oncogenic functions by fibroblasts in response to HIF-1 activation, and one can suggest that HIF-1 is able to drive fibroblast reprogramming to CAFs. Seeming controversially to the described studies, Madsen et al. suggest that long-term hypoxia dampens CAF function in a HIF-1-alfa-dependent way. These authors showed that $72 \mathrm{~h}$ of hypoxic treatment or $72 \mathrm{~h}$ of PHD2 silencing impeded the ability of head and neck CAFs and vulval CAFs to remodel ECM in vivo, which was accompanied by reduced expression of the activated fibroblast marker $\alpha$-SMA. HIF- $1 \alpha$ silencing in these conditions reverted the phenotype. In vivo treatment of breast cancer-bearing mice with PHD-inhibitor DMOG reduced tumour resilience and metastatic potential, while it had no effect on tumour size ${ }^{43}$. This controversy could arise from the fact that CAFs indeed are not identical to normal fibroblasts, originate from different cell types and can develop distinct response. It might also be possible that HIF-1 promotes some of the oncogenic functions of CAFs, such as increasing tumour growth, while inhibiting other oncogenic functions, i.e., metastasis promotion. HIF-2 is known to accumulate and mediate long-term hypoxia responses when HIF- $1 \alpha$ is downregulated. Therefore, metastasis inhibition in longterm hypoxia and some other hypoxic effects of CAFs that are currently thought to be HIF-1 dependent indeed may be regulated by HIF-2. HIF-2 functions in CAFs have been poorly assessed and need further exploration. It is worth mentioning that after $80 \mathrm{~h}$ of hypoxia, normal fibroblasts produce a stiff, aligned matrix and that this matrix supported the migration of breast cancer cells ${ }^{41}$. Taken together, these studies also raise the possibility of different hypoxic responses in CAFs compared to normal fibroblasts.

\section{Extracellular matrix}

The ECM primarily consists of fibrillar proteins and proteoglycans, which together form a net that serves as a 
framework for most tissues ${ }^{44}$. Collagens are the dominant component of the ECM and account for approximately $90 \%$ of its mass ${ }^{45}$. The physical properties of tumour ECM differ from healthy tissue and continuously change ${ }^{46-49}$. In many cases, solid tumours are characterised by excessive deposition of ECM proteins (fibrosis) $)^{50-55}$, and especially by collagen deposition ${ }^{56-61}$. They are the main source for synthesis of ECM proteins, namely collagen, fibronectin and hyaluronan, and on the other hand CAFs are an important source for ECM-remodelling enzymes ${ }^{62}$. CAFs share several features with normal activated fibroblasts, including the ability to produce ECM components, which, on contrary of physiologic microenvironment, results in an abnormal ECM that supports tumour dissemination ${ }^{63}$. ECM and fibroblasts in TME are tightly reciprocally regulated. Modifications of ECM structure or composition induce cytoskeleton reorganisation and signalling cascades in CAFs, further regulating synthesis of ECM components and extracellular remodelling enzymes. Most of these changes in ECM are often supportive for formation of pro-tumorigenic microenvironment ${ }^{64}$. Besides CAFs, cancer cells themselves significantly contribute to ECM remodelling ${ }^{65}$. In breast cancer, localisation of fibrotic areas often coincides with localisation of

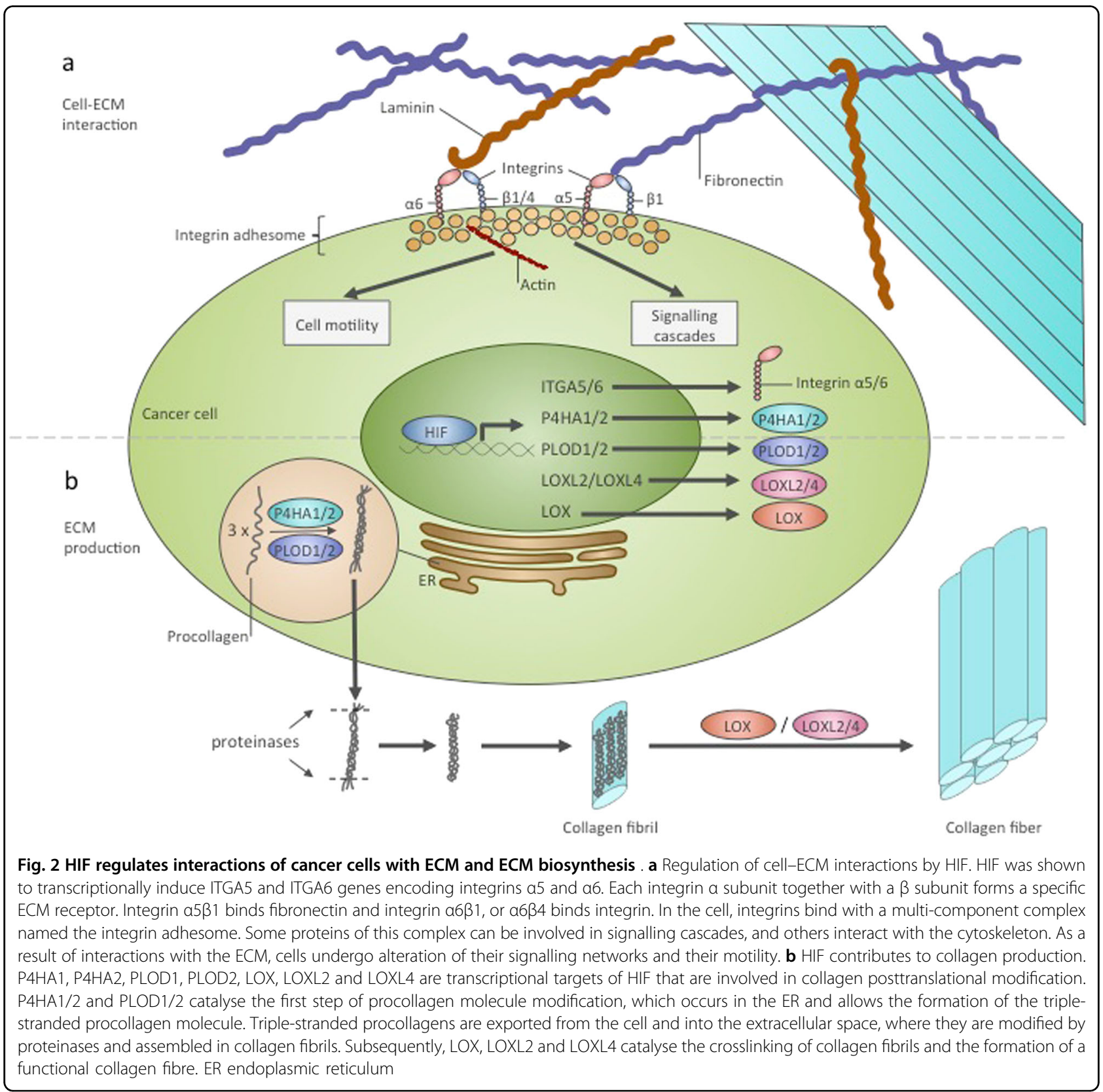


hypoxic regions ${ }^{66,67}$. HIF1 was shown to directly influence ECM remodelling and promote fibrosis in kidney, liver and adipose tissue ${ }^{68-70}$. After hypoxic treatment, rats have increased mRNA levels of procollagens I, II, and IV ${ }^{71}$. Skin, heart and kidney fibroblasts contain elevated mRNA levels of procollagen I $\alpha 1$ chain when cultivated under hypoxic conditions ${ }^{72-74}$. In fibroblasts, fibulin-5 was shown to be transcriptionally induced by hypoxia or in a PHD inhibitor-induced hypoxic environment in a TGF- $\beta$ / PI3K/Akt-dependent way, although the role of HIFs in that process was not assessed ${ }^{75}$. Thus, hypoxia may be able to potentiate ECM protein deposition in tumours in a HIF-dependent and HIF-independent manner (Fig. 1).

The metastatic potential of cancer cells depends on their interactions with the ECM. Cells receive mechanistic signals from the ECM by means of focal adhesions. Formation of focal adhesions requires the binding of ECM proteins with integrins and cell-surface ECM receptors and subsequent signal transduction through intermediate molecules to the cytoskeleton. Silencing of the ITGA5 gene encoding integrin $\alpha 5$, a subunit of fibronectin receptor $\alpha 5 \beta 1$, reduced breast cancer cell motility, migration and invasion capacity. These cells had decreased metastatic potential after orthotopic injection in mice ${ }^{76}$. The same study showed that both HIF-1 and HIF-2 could induce the transcription of integrin subunits $\alpha 5$ and $\beta 1$. Integrin $\alpha 6$ was demonstrated to be a direct transcriptional target of HIF-1 and HIF-2 and to increase breast cancer cell invasion potential ${ }^{77}$. In addition to integrins, another fibronectin receptor, syndecan-4, is transcriptionally induced in hypoxia by an unknown mechanism $^{78}$. Thus, hypoxia is implicated in the regulation of cell-ECM interactions, partially through HIF (Fig. 2). In addition to integrin expression, hypoxia regulates ECM proteins synthesis. HIFs can regulate collagen production at several stages (Fig. 2). Posttranslational modification of procollagen chains requires prolyl-4hydroxylases and procollagen lysyl-hydroxylases. HIF-1 can induce the expression of prolyl-4-hydroxylase alfasubunits P4HA1 and P4HA2 and procollagen lysylhydroxylases PLOD1 and PLOD2 in different cancer and non-cancer cell lines ${ }^{41,79-85}$. Expression of P4HA1, P4HA2, PLOD1 and PLOD2 is necessary for the production of stiff and aligned collagen fibrils. In this microenvironment, cancer cells were shown to take on an elongated, adhesive, motile phenotype and have an elevated capacity for invasion and migration ${ }^{41,81,83,84,86}$.

Another point in the collagen deposition process that is regulated by HIFs is the deamination of secreted collagen fibrils on lysine and hydroxylysine residues by lysyloxidases. This deamination is required for fibril crosslinking and collagen fibre formation ${ }^{87}$. HIF-1 was shown to induce the expression of lysyl-oxidases $\mathrm{LOX}^{88}$, LOXL2 ${ }^{89}$ and LOXL4 $4^{90}$. The LOX family is intimately linked to the metastatic process via several aspects, involving ECM remodelling and potentially ECMindependent EMT regulation ${ }^{91-93}$. The role of LOX expression can be crucial, as lung metastases in a breast cancer model were shown to be dependent on LOXdriven fibrosis ${ }^{94}$. LOX family proteins can mediate several oncogenic HIF-1 functions. LOX knockdown prevented focal adhesion formation and reduced cell motility, abrogating HIF-1-dependent cell migration and inva$\operatorname{sion}^{95}$. In another study, the transformation of cancer cells to an invasive mesenchymal phenotype was dependent on HIF-1-driven LOX and LOXL2 expression ${ }^{89}$. Hypoxic LOX, LOXL2, and LOXL4 secretion by breast cancer cells results in collagen remodelling in lungs, which allows the recruitment of bone-marrow derived cells (BMDCs) to the area. ECM remodelling performed by LOX and BMDC-derived matrix metalloproteinases favours the formation of pre-metastatic niches, showing that the oncogenic ECM remodelling and tumour cell recruitment driven by hypoxia can also have long-distance effects ${ }^{88,90,96}$.

Simultaneous with collagen synthesis, hypoxia promotes the degradation of extracellular matrix. HIF1 is known to induce the expression of matrix metalloproteinases $\mathrm{MMP}^{97}{ }^{97} \mathrm{MMP}^{98}$ and $\mathrm{MMP}^{95^{99}}$ and the expression of urokinase receptor $\mathrm{uPAR}^{97}$. HIF-2 can increase MMP14 levels ${ }^{100}$. Hypoxia-driven expression of these MMPs can promote invasion and correlates with poor patient prognosis $^{97,99,101}$. Downregulation of tissue inhibitors of metalloproteinases TIMP2 and TIMP3 by hypoxia represents an additional level of hypoxic control over ECM remodelling ${ }^{98,102}$. The simultaneous increases in ECM biosynthesis and degradation, which are driven by HIFs, and the hypoxic regulation of focal adhesion formation creates a mechanism for the metastatic spread of cancer cells.

\section{Blood vessels}

Vascularisation is one of the main outcomes of HIF signalling. HIF- $1 \alpha$ and HIF- $2 \alpha$ inactivation led to developmental lethality in mice, which was linked to defects in blood vessel formation ${ }^{103,104}$. A connection between excessive vascularisation and cancer was shown in several models. Redundant vessel formation is considered a feature of cancer, and it promotes cancer progression. Some therapeutic approaches aiming to suppress vascularisation have been developed ${ }^{105-108}$. New vessel development was shown to be important for the transition from hyperplasia to neoplasia ${ }^{109}$. Although vessels transport oxygen, they can be affected by hypoxia. The two major components of blood vessels are endothelial cells and pericytes. Those endothelial cells that reside at the end of growing capillaries and direct their branching are located far from functional vessels, and they can become hypoxic and thus 
develop a hypoxic cellular response ${ }^{110}$. HIF- $1 \alpha$ and HIF$2 \alpha$ presence in endothelial cells differentially affects vascularisation. While HIF- $1 \alpha$ deletion reduces tumour vascularisation and tumour growth, HIF2- $\alpha$ deletion, on the contrary, is able to augment angiogenesis with the formation of a more disorganised vascular system and more hypoxic tumours ${ }^{111-113}$.

Tumours become hypoxic when they grow too large in size apparently because the blood supply is insufficient. At this point, tumour growth decelerates, and HIF1 promotes the secretion of factors inducing vascularisation from tumour and stromal cells; for example, VEGF influences endothelial cells, pericytes and BMDC to induce vessel growth ${ }^{114-116}$. The ECM produced by cancer cells cultured under hypoxic conditions was also shown to support angiogenic growth ${ }^{117,118}$. HIF-induced neovascularization attempts a compensation of the oxygen deficiency in the tumour tissue. But the rate of uncontrollable proliferation of cancer cells exceeds the speed of organised capillary net formation. Indeed sometimes new blood vessels are able to transiently restore the oxygenation, and in this case cancer tissues have interchanging hypoxic areas with a combination of both acute and chronic hypoxic regions. Fluctuations in red cell flux in tumour microvessels can lead to transient hypoxia and reoxygenation in tumour parenchyma ${ }^{119}$. This uncontrolled activation of hypoxia signalling in tumour mass often results in an aberrant, disorganised vascularisation that fails to compensate oxygen deficiency.

It is noteworthy that endothelial cells play an important role in cancer cell migration, as they are the major structural component of blood vessels and serve as a barrier in extravasation and intravasation processes ${ }^{120}$. HIF1- $\alpha$ depletion in endothelial cells was shown to suppress the migration of tumour cells through endothelial cells, but HIF2- $\alpha$ depletion was shown to stimulate metastatic spread. These opposite effects of HIF1- $\alpha$ and HIF2- $\alpha$ on vessel formation and metastasis can be explained by the ability of these factors to differentially regulate the nitric oxide level, which regulates endothelial cell function ${ }^{121}$.

Pericytes are cells embedded in basement membrane of blood microvessels and cover the endothelial cells. They regulate angiogenesis, but also participate to other functions, such as formation of blood-brain barrier. Hypoxic stress of brain pericytes leads to their migration out of the blood vessels, but at the same time HIF-1-signalling leads to VEGF level upregulation and vascularisation stimulation ${ }^{122}$. During the process of kidney fibrosis detachment of pericytes from the capillaries in response to VEGF and PDGF is followed by their transformation to mesenchymal fibroblasts, actively producing $\mathrm{ECM}^{123}$. As both of these factors can be produced in epithelial cells due to HIF-1 signalling, presumably hypoxia in TME could also lead to detachment of pericytes and their subsequent transformation, but this formal experimental evidence in support of this assumption are currently missing.

\section{Lymphatic vessels}

In addition to dissemination in the blood circulation, cancer cells can disseminate through lymphatic vessels. Lymphatic vessel density is increased in breast cancer tissues and correlates with positive lymph node metastases and worsened prognosis ${ }^{124}$. An increased HIF1- $\alpha$ level in primary malignant neoplasias is tightly associated with the density of the surrounding tumour lymphatic vessels and with breast cancer patient mortality ${ }^{125,126}$. In oesophageal cancer, HIF1- $\alpha$ levels correlate with the colonisation of lymph nodes ${ }^{127}$. Different studies suggest a direct contribution of HIF1- $\alpha$ in the regulation of lymphangiogenesis ${ }^{128,129}$. In particular, HIF1- $\alpha$ was proven to induce lymphatic metastases through the activation of different growth factors, including VEGF-c a and PDGF$\mathrm{B}^{33}$. Expression of VEGF-c, one of the major lymphangiogenesis-driving factors, was shown to correlate with HIF1- $\alpha$ expression ${ }^{130}$; however, it remains unclear whether VEGF-c induction requires HIF1- $\alpha$, as the data are controversial ${ }^{131,132}$. HIF1 contribution to lymphatic vessel formation can be mediated by VEGF$\mathrm{a}^{133}$. In contrast, there is evidence for the opposite role of HIF2- $\alpha$ in lymphangiogenesis, as HIF2- $\alpha$ knockdown increased lymphatic vessel formation in vivo in a xenograft model ${ }^{134}$. The influence of hypoxia on lymphatic vessel formation is a poorly studied topic that needs further investigation, as lymphatic vessel formation contributes to metastatic tumour spread.

\section{Immune cells}

Adaptive immune cells can potentially inhibit tumour growth by the recognition of tumour-specific antigens on the surface of cancer cells and the elimination of those cells. Innate immune cells can promote the antitumour activity of infiltrating lymphocytes and lead to significant tumour regression. HIFs have been shown to be tightly connected with the inflammatory processes ${ }^{135,136}$, and hypoxia can directly or indirectly influence the function of almost all immune cell types, thereby influencing tumour development ${ }^{137}$.

\section{Innate tumour immunity}

Myeloid cell-specific PHD2 depletion was shown to suppress tumour growth and metastases, underlining the importance of oxygen sensitivity for myeloid cells ${ }^{138}$. A hypoxic TME is known to promote neutrophil engagement in tumours by regulation of their adherence to epithelial cells ${ }^{139,140}$. HIF1- $\alpha$ and HIF2- $\alpha$ were separately shown to increase the survival and function of neutrophils $^{141-144}$. The outcome of this hypoxic effect is still 
unknown, as cancer-associated neutrophils can induce both tumour suppression and tumour progression ${ }^{145}$.

An increase in cancer-associated macrophage density correlates with poor patient prognosis in different types of cancer ${ }^{146,147}$. Macrophage polarisation plays a significant role in tumorigenesis. Indeed, macrophages polarised to the M1 type (classical activation) counteract cancer progression and metastases, while M2-polarised macrophages (alternative activation) can promote it ${ }^{148}$. Hypoxia induces tumour cells to secrete chemoattractants, such as Sema3A, EMAPII, ET-1 and ET-2, promoting the chemotaxis of macrophages from the circulation ${ }^{149-151}$. HIF1- $\alpha$ was shown to be necessary for macrophage maturation, function ${ }^{141}$ and glycolytic reprogramming and when associated with HIF1- $\alpha$-induced PDK1 activity, it increases the migratory capacity of macrophages, representing a possible mechanism of macrophage infiltration regulation by HIF1- $\alpha^{152}$. In addition, hypoxia determines macrophage polarisation through the induction of M2 polarisation-related genes ${ }^{153}$ and promotes lactic-acid-induced M2 polarisation ${ }^{154}$. In vivo experiments show that HIF1- $\alpha$ and HIF2- $\alpha$ are both crucial for macrophage infiltration and immune suppression in tumours, as their separate ablation led to reduced tumour growth $^{155,156}$.

Another noteworthy innate immune cell is the myeloidderived suppressor cell (MDSC). These cells originate from bone marrow cells, and their numbers are significantly increased in cancer. Their main feature is the ability to suppress the activity of other immune cells and therefore suppress the antitumour immune response ${ }^{157}$. The role of hypoxia in MDSC regulation has been considered mostly oncogenic. Hypoxia-treated MDSCs show activation of HIF-signalling and of those HIF targets that enhance MDSC function ${ }^{158}$. Hypoxia can also augment MDSC function through a mechanism partially dependent on HIF: by miR-210 regulation and ArgI expres$\operatorname{sion}^{158,159}$. However, some studies suggest that MDSCs are able to gain immunostimulatory properties ${ }^{160}$. Liu and Colleagues described MDSCs' differentiation into the tumour-suppressing M1 subtype after SIRT1 induction, and this differentiation occurred as a result of mTOR/ HIF-1 $\alpha$-dependent glycolytic reprogramming ${ }^{161}$. This observation suggests that HIF1 may also endow MDSCs with tumour-suppressive functions and that the role of HIFs in MDSC regulation needs to be further investigated.

\section{Adaptive tumour immunity}

Although T-cells are able to infiltrate into the tumour, anticancer immunity is often limited due to characteristics of the TME and a hypoxic environment ${ }^{162}$. Increased glycolysis in the tumour, which is partially mediated by HIF activity, is a reason for so-called "metabolic competition" between cancer cells and T- cells. Lack of nutrients suppresses T-cell function and the antitumour response $\mathrm{e}^{163-165}$. Hypoxia induces the differentiation of non-specific CD4+ T-cells into regulatory $\mathrm{T}$ cells (CD4 + CD25 ${ }^{\text {High }}$ FOXP3+) or T-helpers (TH17), and expression of transcriptional factors FOXP3 and ROR $\gamma \mathrm{t}$, which are crucial for differentiation, is regulated by HIF$1^{166-168}$. While regulatory T-cells have immunosuppressive functions, the contribution of TH17 cells to the immune response is unclear ${ }^{169}$. In addition, under hypoxic conditions, cancer cells and macrophages synthesise chemokines and cytokines, which attract regulatory T-cells from the circulation and repress the antitumour response of other $\mathrm{T}$-cells ${ }^{170-172}$. Regulatory T-cells in hypoxia produce extracellular adenosine, which represses effector T-cell function ${ }^{173,174}$. Another mechanism of effector $\mathrm{T}$-cell suppression involves a hypoxia-dependent increase in lysyl oxidase secretion, which causes the formation of premetastatic niches. MDSCs can migrate into those niches and suppress the anti-tumour response of T-killers ${ }^{95,175,176}$.

HIF1 is involved in the regulation of T-cell immune checkpoints (Fig. 3). In cancer cells, macrophages, dendritic cells and MDSCs, HIF1- $\alpha$ directly induces PD-L1 expression ${ }^{177-179}$. Binding of PD-L1 expressed on the cell surface to the PD-1 receptor on T-cells leads to their dysfunction, and hence, this mechanism is a target for different pharmaceutical approaches, such as the development of anti-PD-L1 antibodies and PD-1/PD-L1 interaction inhibitors ${ }^{180,181}$. Another checkpoint regulated by hypoxia is the CTLA-4 receptor, which is upregulated on $\mathrm{CD} 8+\mathrm{T}$-cells in hypoxia potentially via HIF $1^{182}$. Binding of CTLA-4 on T-cells to ligands CD80 and CD86 on the surface of antigen-presenting cells results in effector $\mathrm{T}$-cell inhibition and regulatory $\mathrm{T}$-cell activation $^{183}$. As with PD-1, anti-cancer treatments using CTLA-4 blocking antibodies have been developed. CTLA4 and PD-1/PD-L1-targeted therapies showed positive responses in clinical trials for several types of cancer ${ }^{184-}$ ${ }^{186}$. However, the outcome of the therapies is dependent on many parameters, including the frequency of tumourinfiltrating lymphocytes, which inversely correlates with the glycolytic rate and HIF1- $\alpha$ expression ${ }^{187,188}$.

In contrast to the described effector $\mathrm{T}$-cell suppression by hypoxia, some data indicate that HIF function is important for the activity of effector cytotoxic T-cells. It was shown by Doedens and colleagues in 2013 that elevated HIF-1 and HIF-2 support the function of cytotoxic $\mathrm{CD} 8+\mathrm{T}$-cells ${ }^{182}$. In agreement with these findings, a recent study by Tyrakis et al. has suggested a role for HIF1- $\alpha$ in CD8 + T-cell proliferation, differentiation and antitumour activity through the regulation of $\mathrm{L}-2 \mathrm{HG}^{189}$. Apart from cytotoxic T-cells, HIF-1 was also shown to contribute to natural killer cell priming and activation via 


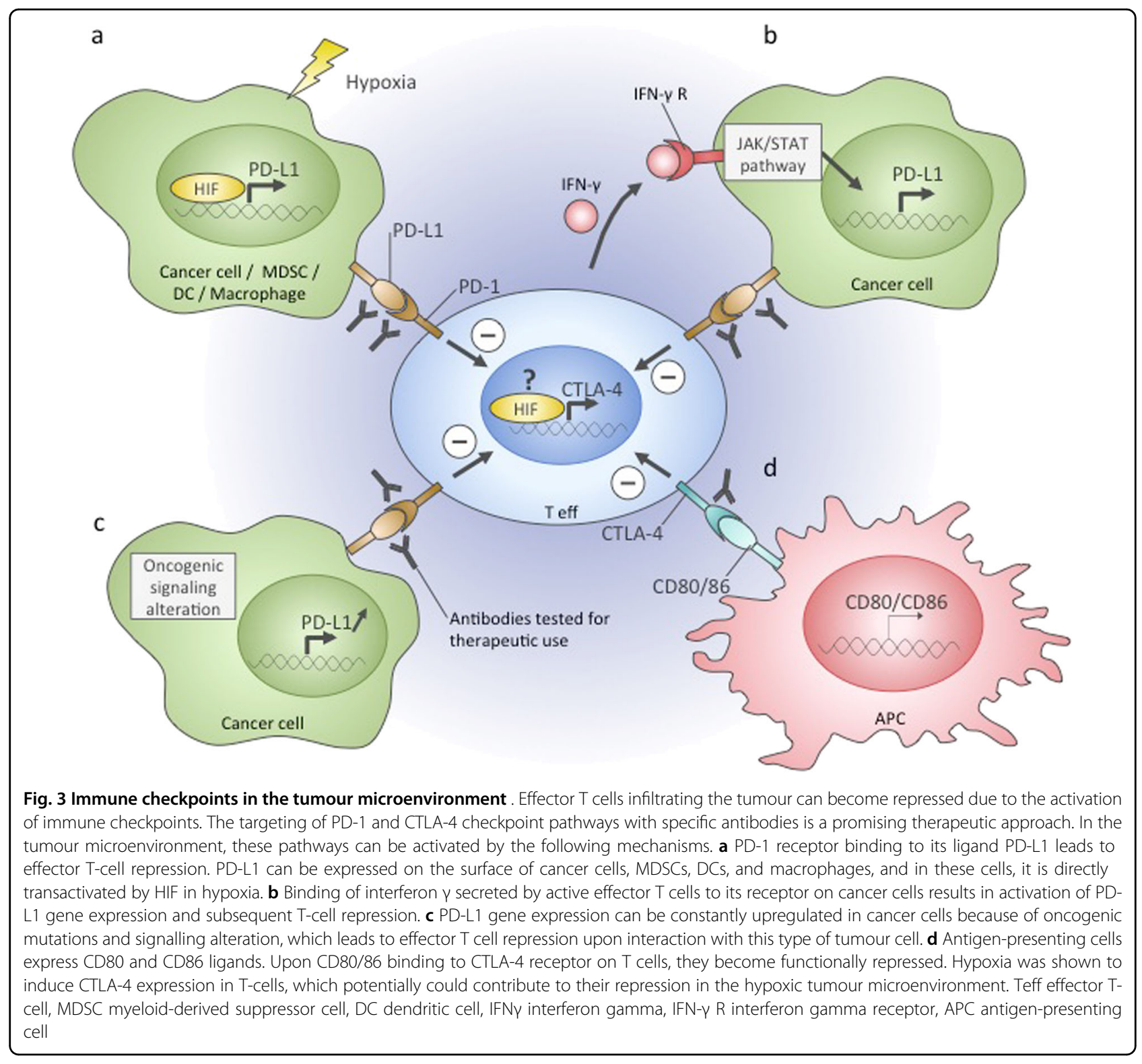

regulation of the glycolytic rate ${ }^{190}$, thus demonstrating a stimulatory role in immune activation.

\section{Conclusions}

The role of TME in cancer progression is currently attracting impressive interest in the field. Hypoxia is a condition that often occurs at late stages of cancer, and even before that, HIFs can be upregulated due to environmental acidification and the presence of glycolytic metabolites ${ }^{191-193}$. The HIF-mediated hypoxic impact on TME in most cases is mediated by transcriptional activity of HIFs, secretion of signalling molecules by cancer cells and tumour stromal cells, and metabolic changes associated with the switch from oxygen-dependent catabolism to glycolysis. Non-tumorous cells in the TME are all affected by hypoxia and HIFs (Table 1). Often, hypoxia leads to their dysregulation in a way that supports cancer growth: fibroblasts can be transformed into tumour-prone CAFs, ECM remodelling supports metastases, vascularisation process facilitates cancer progression, and antitumour immune function becomes generally repressed. Nevertheless, the hypoxic response can also be detrimental for tumorigenesis (Table 1). This finding can be partially explained by the differences in HIF-1 and HIF-2 stability and function, as acute hypoxic response is mainly mediated by HIF1 activity, and chronic hypoxia by HIF2 ${ }^{194}$. Dual roles can also arise from the presence of HIF interactors, among which the p53 family and MDM2 can play important roles, as they can affect HIF stability and function ${ }^{195,196}$. In this context, the interplay between 
Table 1 Influence of hypoxia on TME components

\begin{tabular}{|c|c|c|}
\hline TME component & Influence of hypoxic environment & Cancer suppression (+)/promotion (-) \\
\hline CAF progenitors & Recruitment, activation and transformation into CAFs & - \\
\hline \multirow[t]{2}{*}{ CAFs } & Secretion of cytokines, promoting tumour growth & - \\
\hline & Deactivation by chronic hypoxia & + \\
\hline \multirow[t]{2}{*}{ ECM } & Increase of ECM deposition (fibrosis) and remodelling & - \\
\hline & Increase of interaction with cancer cells & - \\
\hline \multirow[t]{2}{*}{ Blood vessels } & Increase in vascularisation by HIF-1 & - \\
\hline & Decrease in vascularisation by HIF-2 & + \\
\hline \multirow[t]{2}{*}{ Lymphatic vessels } & Increase in lymphangiogenesis by HIF-1 & - \\
\hline & Decrease in lymphangiogenesis by HIF-2 & $?$ \\
\hline \multirow[t]{2}{*}{ Neutrophils } & Recruitment to tumour & $?$ \\
\hline & Increase in survival and function & $?$ \\
\hline \multirow[t]{4}{*}{ Macrophage } & Maturation and functioning are dependent on HIF1 & $?$ \\
\hline & Recruitment from bloodflow & - \\
\hline & Increase in migratory capacity & - \\
\hline & M2 polarisation & - \\
\hline \multirow[t]{2}{*}{ MDSCs } & Enhancement of immune-suppressive function & - \\
\hline & Polarisation to M1 type, driven by SIRT1 & + \\
\hline Non-specific CD4+ cells & Differentiation into regulatory T-cells and T-helpers & $-/ ?$ \\
\hline \multirow[t]{2}{*}{ Regulatory T-cells } & Recruitment from bloodflow & - \\
\hline & Enhancement of immune suppressive function & - \\
\hline \multirow[t]{2}{*}{ Effector T-cells } & Immune checkpoints activation & - \\
\hline & Repression due to "metabolic competition" for nutrients & - \\
\hline CD8+ T-cells & Support in proliferation, differentiation and activation & + \\
\hline
\end{tabular}

HIF and the p53 family can influence a wide range of cellular processes specifically associated with complexity of p53 family members in controlling cell death ${ }^{197-201}$, metabolism $^{202-207}$, reproduction ${ }^{208,209}$, and development $^{210-213}$.

Considering the global impact of HIF on cancer cells and the TME, therapies targeting HIF activity, such as the usage of small molecules preventing the interactions of the HIF- $\alpha$ and HIF1- $\beta$ subunits ${ }^{214}$, can be beneficial for some groups of patients.

\section{Author details}

${ }^{1}$ Medical Research Council, Toxicology Unit, Leicester University, Hodgkin Building, Lancaster RoadP.O. Box 138, Leicester LE1 9HN, UK. Biochemistry Laboratory, IDI-IRCCS, Rome, Italy. ${ }^{3}$ Department of Experimental Medicine and Surgery, University of Rome "Tor Vergata", 00133 Rome, Italy

\section{Conflict of interest}

The authors declare that they have no competing interests.
Received: 31 July 2017 Accepted: 4 October 2017

Published online: 24 January 2018

\section{References}

1. Balkwill, F. R., Capasso, M. \& Hagemann, T. The tumor microenvironment at a glance. J. Cell. Sci. 125, 5591-5596 (2012).

2. Pouyssegur, J., Dayan, F. \& Mazure, N. M. Hypoxia signalling in cancer and approaches to enforce tumour regression. Nature 441, 437-443 (2006).

3. Wang, G. L., Jiang, B. H., Rue, E. A. \& Semenza, G. L. Hypoxia-inducible factor 1 is a basic-helix-loop-helix-PAS heterodimer regulated by cellular $\mathrm{O} 2$ tension. Proc. Natl. Acad. Sci. USA 92, 5510-5514 (1995).

4. Jaakkola, P. et al. Targeting of HIF-alpha to the von Hippel-Lindau ubiquitylation complex by O2-regulated prolyl hydroxylation. Science $\mathbf{2 9 2}$, 468-472 (2001).

5. Ohh, M. et al. Ubiquitination of hypoxia-inducible factor requires direct binding to the beta-domain of the von Hippel-Lindau protein. Nat. Cell. Biol. 2, 423-427 (2000).

6. Koivunen, P., Hirsila, M., Gunzler, V., Kivirikko, K. I. \& Myllyharju, J. Catalytic properties of the asparaginyl hydroxylase $(F \mid H)$ in the oxygen sensing pathway are distinct from those of its prolyl 4-hydroxylases. J. Biol. Chem. 279, 9899-9904 (2004).

7. Mahon, P. C., Hirota, K. \& Semenza, G. L. FlH-1: a novel protein that interacts with HIF-1alpha and $\mathrm{VHL}$ to mediate repression of HIF-1 transcriptional activity. Genes. Dev. 15, 2675-2686 (2001). 
8. Mandl, M., Lieberum, M. K. \& Depping, R. A HIF-1alpha-driven feed-forward loop augments HIF signalling in Hep3B cells by upregulation of ARNT. Cell. Death Dis. 7, e2284 (2016).

9. Olive, K. P. et al. Inhibition of Hedgehog signaling enhances delivery of chemotherapy in a mouse model of pancreatic cancer. Science 324, 1457-1461 (2009).

10. Baroni, S. et al. Exosome-mediated delivery of miR-9 induces cancerassociated fibroblast-like properties in human breast fibroblasts. Cell. Death Dis. 7, e2312 (2016)

11. Bochet, L. et al. Adipocyte-derived fibroblasts promote tumor progression and contribute to the desmoplastic reaction in breast cancer. Cancer Res. $\mathbf{7 3}$ 5657-5668 (2013).

12. Lecomte, J. et al. Bone marrow-derived myofibroblasts are the providers of pro-invasive matrix metalloproteinase 13 in primary tumor. Neoplasia $\mathbf{1 4}$ 943-951 (2012).

13. McDonald, L. T. et al. Hematopoietic stem cell-derived cancer-associated fibroblasts are novel contributors to the pro-tumorigenic microenvironment Neoplasia 17, 434-448 (2015).

14. Quante, M. et al. Bone marrow-derived myofibroblasts contribute to the mesenchymal stem cell niche and promote tumor growth. Cancer Cell. 19, 257-272 (2011)

15. Radisky, D. C., Kenny, P. A. \& Bissell, M. J. Fibrosis and cancer: do myofibroblasts come also from epithelial cells via EMT? J. Cell. Biochem. 101, 830-839 (2007).

16. Tang, $X$. et al. Stromal miR-200s contribute to breast cancer cell invasion through CAF activation and ECM remodeling. Cell. Death. Differ. 23, 132-145 (2016)

17. Zeisberg, E. M., Potenta, S., Xie, L., Zeisberg, M. \& Kalluri, R. Discovery of endothelial to mesenchymal transition as a source for carcinoma-associated fibroblasts. Cancer Res. 67, 10123-10128 (2007)

18. Olaso, E. et al. Tumor-dependent activation of rodent hepatic stellate cells during experimental melanoma metastasis. Hepatology 26, 634-642 (1997).

19. Olumi, A. F. et al. Carcinoma-associated fibroblasts direct tumor progression of initiated human prostatic epithelium. Cancer Res. 59, 5002-5011 (1999).

20. Bhowmick, N. A. et al. TGF-beta signaling in fibroblasts modulates the oncogenic potential of adjacent epithelia. Science 303, 848-851 (2004).

21. Grum-Schwensen, B. et al. Suppression of tumor development and metastasis formation in mice lacking the S100A4(mts1) gene. Cancer Res. $\mathbf{6 5}$ 3772-3780 (2005).

22. Orimo, A et al. Stromal fibroblasts present in invasive human breast carcinomas promote tumor growth and angiogenesis through elevated SDF-1/ CXCL12 secretion. Cell 121, 335-348 (2005).

23. Dumont, N. et al. Breast fibroblasts modulate early dissemination, tumorigenesis, and metastasis through alteration of extracellular matrix characteristics. Neoplasia 15, 249-262 (2013).

24. Fornetti, J. et al. Mammary epithelial cell phagocytosis downstream of TGFbeta3 is characterized by adherens junction reorganization. Cell. Death. Differ. 23, 185-196 (2016).

25. Ghavami, S. et al. Autophagy is a regulator of TGF-beta1-induced fibrogenesis in primary human atrial myofibroblasts. Cell. Death Dis. 6, e1696 (2015).

26. Wang, X. et al. Upregulation of MiR-205 under hypoxia promotes epithelialmesenchymal transition by targeting ASPP2. Cell. Death Dis. 7, e2517 (2016).

27. Pietras, K. \& Ostman, A. Hallmarks of cancer: interactions with the tumor stroma. Exp. Cell. Res. 316, 1324-1331 (2010).

28. Ammirante, M., Shalapour, S., Kang, Y., Jamieson, C. A. \& Karin, M. Tissue injury and hypoxia promote malignant progression of prostate cancer by inducing CXCL13 expression in tumor myofibroblasts. Proc. Natl. Acad. Sci. USA 111 14776-14781 (2014).

29. Schioppa, T. et al. Regulation of the chemokine receptor CXCR4 by hypoxia. J. Exp. Med. 198, 1391-1402 (2003).

30. Gilkes, D. M., Semenza, G. L. \& Wirtz, D. Hypoxia and the extracellular matrix: drivers of tumour metastasis. Nat. Rev. Cancer 14, 430-439 (2014).

31. Caniggia, I. et al. Hypoxia-inducible factor-1 mediates the biological effects of oxygen on human trophoblast differentiation through TGFbeta(3). J. Clin. Invest. 105, 577-587 (2000).

32. Moeller, B. J., Cao, Y., Li, C. Y. \& Dewhirst, M. W. Radiation activates HIF-1 to regulate vascular radiosensitivity in tumors: role of reoxygenation, free radicals, and stress granules. Cancer Cell. 5, 429-441 (2004).

33. Schito, L. et al. Hypoxia-inducible factor 1-dependent expression of plateletderived growth factor B promotes lymphatic metastasis of hypoxic breast cancer cells. Proc. Natl. Acad. Sci. USA 109, E2707-2716 (2012).
34. Fiaschi, T. et al. Reciprocal metabolic reprogramming through lactate shuttle coordinately influences tumor-stroma interplay. Cancer Res. 72, 5130-5140 (2012)

35. Zhang, D. et al. Metabolic reprogramming of cancer-associated fibroblasts by IDH3alpha downregulation. Cell. Rep. 10, 1335-1348 (2015).

36. Chiavarina, B. et al. HIF1-alpha functions as a tumor promoter in cancer associated fibroblasts, and as a tumor suppressor in breast cancer cells: Autophagy drives compartment-specific oncogenesis. Cell. Cycle $\mathbf{9}$ 3534-3551 (2010).

37. Jawhari, S., Ratinaud, M. H. \& Verdier, M. Glioblastoma, hypoxia and autophagy: a survival-prone 'menage-a-trois'. Cell. Death Dis. 7, e2434 (2016).

38. Qi, Y. et al. PTEN induces apoptosis and cavitation via HIF-2-dependent Bnip3 upregulation during epithelial lumen formation. Cell. Death. Differ. 22, 875-884 (2015)

39. Sukumaran, P., Sun, Y., Vyas, M. \& Singh, B. B. TRPC1-mediated Ca(2)(+) entry is essential for the regulation of hypoxia and nutrient depletion-dependent autophagy. Cell. Death Dis. 6, e1674 (2015).

40. Kim, J. W. et al. Loss of fibroblast HIF-1alpha accelerates tumorigenesis. Cancer Res. 72, 3187-3195 (2012).

41. Gilkes, D. M., Bajpai, S., Chaturvedi, P., Wirtz, D. \& Semenza, G. L. Hypoxiainducible factor 1 (HIF-1) promotes extracellular matrix remodeling under hypoxic conditions by inducing P4HA1, P4HA2, and PLOD2 expression in fibroblasts. J. Biol. Chem. 288, 10819-10829 (2013).

42. Ide, T. et al. Tumor-stromal cell interaction under hypoxia increases the invasiveness of pancreatic cancer cells through the hepatocyte growth factor/c-Met pathway. Int. J. Cancer 119, 2750-2759 (2006).

43. Madsen, C. D. et al. Hypoxia and loss of PHD2 inactivate stromal fibroblasts to decrease tumour stiffness and metastasis. Embo. Rep. 16, 1394-1408 (2015).

44. Frantz, C., Stewart, K. M. \& Weaver, V. M. The extracellular matrix at a glance. J. Cell. Sci. 123, 4195-4200 (2010).

45. van der Rest, M. \& Garrone, R. Collagen family of proteins. Faseb J. 5, 2814-2823 (1991).

46. Chen, S. Z. et al. The miR-181d-regulated metalloproteinase Adamts1 enzymatically impairs adipogenesis via ECM remodeling. Cell. Death Differ. 23, 1778-1791 (2016).

47. Clarijs, R., Ruiter, D. J. \& De Waal, R. M. Pathophysiological implications of stroma pattern formation in uveal melanoma. J. Cell. Physiol. 194, 267-271 (2003).

48. Oh, S. Y., Lee, S. J., Jung, Y. H., Lee, H. J. \& Han, H. J. Arachidonic acid promotes skin wound healing through induction of human MSC migration by MT3MMP-mediated fibronectin degradation. Cell. Death Dis. 6, e1750 (2015).

49. van Kempen, L. C., Ruiter, D. J., van Muijen, G. N. \& Coussens, L. M. The tumor microenvironment: a critical determinant of neoplastic evolution. Eur. J. Cell. Biol. 82, 539-548 (2003).

50. Artinian, V. \& Kvale, P. A. Cancer and interstitial lung disease. Curr. Opin. Pulm. Med. 10, 425-434 (2004).

51. Bissell, D. M. Chronic liver injury, TGF-beta, and cancer. Exp. Mol. Med. 33 179-190 (2001)

52. Boyd, N. F. Jensen, H. M. Cooke, G. \& Han, H. L. Relationship between mammographic and histological risk factors for breast cancer. J. Natl. Cancer Inst. 84, 1170-1179 (1992).

53. Boyd, N. F. et al. Mammographic densities and the prevalence and incidence of histological types of benign breast disease. Reference Pathologists of the Canadian National Breast Screening Study. Eur. J. Cancer Prev. 9, 15-24 (2000).

54. Boyd, N. F. et al. Heritability of mammographic density, a risk factor for breast cancer. N. Engl. J. Med. 347, 886-894 (2002).

55. Zhao, J., Du, F., Shen, G., Zheng, F. \& Xu, B. The role of hypoxia-inducible factor-2 in digestive system cancers. Cell. Death Dis. 6, e1600 (2015).

56. Coussens, L. M. et al. Inflammatory mast cells up-regulate angiogenesis during squamous epithelial carcinogenesis. Genes. Dev. 13, 1382-1397 (1999).

57. Gould, V. E., Koukoulis, G. K. \& Virtanen, I. Extracellular matrix proteins and their receptors in the normal, hyperplastic and neoplastic breast. Cell. Differ. Dev. 32, 409-416 (1990).

58. Huijbers, I. J. et al. A role for fibrillar collagen deposition and the collagen internalization receptor endo180 in glioma invasion. PLoS. One 5, e9808 (2010)

59. Kauppila, S., Stenback, F., Risteli, J., Jukkola, A. \& Risteli, L. Aberrant type I and type III collagen gene expression in human breast cancer in vivo. J. Pathol. 186, 262-268 (1998).

60. Shapiro, F. D. \& Eyre, D. R. Collagen polymorphism in extracellular matrix of human osteosarcoma. J. Natl. Cancer Inst. 69, 1009-1016 (1982). 
61. Zhu, G. G. et al. Immunohistochemical study of type I collagen and type I pNcollagen in benign and malignant ovarian neoplasms. Cancer 75, 1010-1017 (1995).

62. Cirri, P. \& Chiarugi, P. Cancer associated fibroblasts: the dark side of the coin. Am. J. Cancer Res. 1, 482-497 (2011).

63. Kalluri, R. The biology and function of fibroblasts in cancer. Nat. Rev. Cancer 16, 582-598 (2016)

64. Alexander, J. \& Cukierman, E. Stromal dynamic reciprocity in cancer: intricacies of fibroblastic-ECM interactions. Curr. Opin. Cell. Biol. 42, 80-93 (2016)

65. Ungefroren, H., Sebens, S., Seidl, D., Lehnert, H. \& Hass, R. Interaction of tumor cells with the microenvironment. Cell. Commun. Signal. 9, 18 (2011).

66. Colpaert, C. G. et al. The presence of a fibrotic focus in invasive breast carcinoma correlates with the expression of carbonic anhydrase IX and is a marker of hypoxia and poor prognosis. Breast Cancer Res. Treat. 81, 137-147 (2003).

67. Trastour, C. et al. HIF-1alpha and CA IX staining in invasive breast carcinomas: prognosis and treatment outcome. Int. J. Cancer 120, 1451-1458 (2007).

68. Halberg, N. et al. Hypoxia-inducible factor 1alpha induces fibrosis and insulin resistance in white adipose tissue. Mol. Cell. Biol. 29, 4467-4483 (2009).

69. Higgins, D. F. et al. Hypoxia promotes fibrogenesis in vivo via HIF-1 stimulation of epithelial-to-mesenchymal transition. J. Clin. Invest. 117, 3810-3820 (2007).

70. Moon, J. O., Welch, T. P., Gonzalez, F. J. \& Copple, B. L. Reduced liver fibrosis in hypoxia-inducible factor-1alpha-deficient mice. Am. J. Physiol. Gastrointest. Liver Physiol. 296, G582-592 (2009).

71. Berg, J. T., Breen, E. C., Fu, Z., Mathieu-Costello, O. \& West, J. B. Alveolar hypoxia increases gene expression of extracellular matrix proteins and platelet-derived growth factor-B in lung parenchyma. Am. J. Respir. Crit. Care Med. 158, 1920-1928 (1998).

72. Falanga, $V$. et al. Low oxygen tension increases mRNA levels of alpha 1 (I) procollagen in human dermal fibroblasts. J. Cell. Physiol. 157, 408-412 (1993).

73. Norman, J. T., Clark, I. M. \& Garcia, P. L. Hypoxia promotes fibrogenesis in human renal fibroblasts. Kidney Int. 58, 2351-2366 (2000).

74. Tamamori, M., Ito, H., Hiroe, M., Marumo, F. \& Hata, R. I. Stimulation of collagen synthesis in rat cardiac fibroblasts by exposure to hypoxic culture conditions and suppression of the effect by natriuretic peptides. Cell. Biol. Int. 21, 175-180 (1997)

75. Topalovski, M., Hagopian, M., Wang, M. \& Brekken, R. A. Hypoxia and transforming growth factor beta cooperate to induce fibulin-5 expression in pancreatic cancer. J. Biol. Chem. 291, 22244-22252 (2016).

76. Ju, J. A. et al. Hypoxia selectively enhances integrin receptor expression to promote metastasis. Mol Cancer Res. 15, 723-734 (2017).

77. Brooks, D. L. et al. ITGA6 is directly regulated by hypoxia-inducible factors and enriches for cancer stem cell activity and invasion in metastatic breast cancer models. Mol. Cancer 15, 26 (2016).

78. Koike, T. et al. Hypoxia induces adhesion molecules on cancer cells: a missing link between Warburg effect and induction of selectin-ligand carbohydrates. Proc. Natl. Acad. Sci. USA 101, 8132-8137 (2004).

79. Aro, E. et al. Hypoxia-inducible factor-1 (HIF-1) but not HIF-2 is essential for hypoxic induction of collagen prolyl 4-hydroxylases in primary newborn mouse epiphyseal growth plate chondrocytes. J. Biol. Chem. 287, 37134-37144 (2012).

80. Bentovim, L., Amarilio, R. \& Zelzer, E. HIF1alpha is a central regulator of collagen hydroxylation and secretion under hypoxia during bone development. Development 139, 4473-4483 (2012).

81. Eisinger-Mathason, T. S. et al. Hypoxia-dependent modification of collagen networks promotes sarcoma metastasis. Cancer Discov. 3, 1190-1205 (2013).

82. Elvidge, G. P. et al. Concordant regulation of gene expression by hypoxia and 2-oxoglutarate-dependent dioxygenase inhibition: the role of HIF-1alpha, HIF-2alpha, and other pathways. J. Biol. Chem. 281, 15215-15226 (2006).

83. Gilkes, D. M. et al. Procollagen lysyl hydroxylase 2 is essential for hypoxiainduced breast cancer metastasis. Mol. Cancer Res. 11, 456-466 (2013).

84. Gilkes, D. M. et al. Collagen prolyl hydroxylases are essential for breast cancer metastasis. Cancer Res. 73, 3285-3296 (2013).

85. Hofbauer, K. H. et al. Oxygen tension regulates the expression of a group of procollagen hydroxylases. Eur. J. Biochem. 270, 4515-4522 (2003).

86. Xiong, G., Deng, L., Zhu, J., Rychahou, P. G. \& Xu, R. Prolyl-4-hydroxylase alpha subunit 2 promotes breast cancer progression and metastasis by regulating collagen deposition. BMC Cancer 14, 1 (2014).

87. Gordon, M. K. \& Hahn, R. A. Collagens. Cell. Tissue Res. 339, 247-257 (2010).
88. Erler, J. T. et al. Hypoxia-induced lysyl oxidase is a critical mediator of bone marrow cell recruitment to form the premetastatic niche. Cancer Cell. 15, 35-44 (2009)

89. Schietke, R. et al. The lysyl oxidases LOX and LOXL2 are necessary and sufficient to repress E-cadherin in hypoxia: insights into cellular transformation processes mediated by HIF-1. J. Biol. Chem. 285, 6658-6669 (2010).

90. Wong, C. C. et al. Hypoxia-inducible factor 1 is a master regulator of breast cancer metastatic niche formation. Proc. Natl. Acad. Sci. USA 108, 16369-16374 (2011).

91. Barker, H. E., Cox, T. R. \& Erler, J. T. The rationale for targeting the LOX family in cancer. Nat. Rev. Cancer 12, 540-552 (2012).

92. Li, X. et al. Negative feedback loop between p66Shc and ZEB1 regulates fibrotic EMT response in lung cancer cells. Cell. Death Dis. 6, e1708 (2015).

93. Yun-Ju Huang, R. \& Yo-Yan Huang, T. A new dimension in drug discovery: reversing epithelial-mesenchymal transition (EMT). Cell. Death Dis. 7, e2417 (2016)

94. Cox, T. R. et al. LOX-mediated collagen crosslinking is responsible for fibrosisenhanced metastasis. Cancer Res. 73, 1721-1732 (2013).

95. Erler, J. T. et al. Lysyl oxidase is essential for hypoxia-induced metastasis. Nature 440, 1222-1226 (2006).

96. Wong, C. C. et al. Inhibitors of hypoxia-inducible factor 1 block breast cancer metastatic niche formation and lung metastasis. J. Mol. Med. 90, 803-815 (2012)

97. Krishnamachary, B. et al. Regulation of colon carcinoma cell invasion by hypoxia-inducible factor 1. Cancer Res. 63, 1138-1143 (2003).

98. Choi, J. Y., Jang, Y. S., Min, S. Y. \& Song, J. Y. Overexpression of MMP-9 and HIF-1alpha in breast cancer cells under hypoxic conditions. J. Breast Cancer 14, 88-95 (2011)

99. Zhu, S. K. et al. Overexpression of membrane-type 2 matrix metalloproteinase induced by hypoxia-inducible factor-1alpha in pancreatic cancer: Implications for tumor progression and prognosis. Mol. Clin. Oncol. 2, 973-981 (2014)

100. Petrella, B. L., Lohi, J. \& Brinckerhoff, C. E. Identification of membrane type-1 matrix metalloproteinase as a target of hypoxia-inducible factor-2 alpha in von Hippel-Lindau renal cell carcinoma. Oncogene 24, 1043-1052 (2005).

101. Munoz-Najar, U. M., Neurath, K. M., Vumbaca, F. \& Claffey, K. P. Hypoxia stimulates breast carcinoma cell invasion through MT1-MMP and MMP-2 activation. Oncogene 25, 2379-2392 (2006).

102. Kai, A. K. et al. Down-regulation of TIMP2 by HIF-1alpha/miR-210/HIF-3alpha regulatory feedback circuit enhances cancer metastasis in hepatocellular carcinoma. Hepatology 64, 473-487 (2016).

103. Iyer, N. V. et al. Cellular and developmental control of $\mathrm{O} 2$ homeostasis by hypoxia-inducible factor 1 alpha. Genes. Dev. 12, 149-162 (1998).

104. Peng, J., Zhang, L., Drysdale, L. \& Fong, G. H. The transcription factor EPAS-1/ hypoxia-inducible factor 2alpha plays an important role in vascular remodeling. Proc. Natl. Acad. Sci. USA 97, 8386-8391 (2000)

105. Bergers, G. \& Benjamin, L. E. Tumorigenesis and the angiogenic switch. Nat Rev. Cancer 3, 401-410 (2003).

106. Carmeliet, P. \& Jain, R. K. Molecular mechanisms and clinical applications of angiogenesis. Nature 473, 298-307 (2011).

107. Ferrara, N. \& Kerbel, R. S. Angiogenesis as a therapeutic target. Nature $\mathbf{4 3 8}$ 967-974 (2005)

108. Watson, E. C., Whitehead, L., Adams, R. H., Dewson, G. \& Coultas, L. Endothelial cell survival during angiogenesis requires the pro-survival protein MCL1. Cell. Death. Differ. 23, 1371-1379 (2016)

109. Folkman, J., Watson, K. Ingber, D. \& Hanahan, D. Induction of angiogenesis during the transition from hyperplasia to neoplasia. Nature 339, 58-61 (1989).

110. Coulon, C. et al. From vessel sprouting to normalization: role of the proly hydroxylase domain protein/hypoxia-inducible factor oxygen-sensing machinery. Arterioscler. Thromb. Vasc. Biol. 30, 2331-2336 (2010).

111. Skuli, N. et al. Endothelial deletion of hypoxia-inducible factor-2alpha (HIF2alpha) alters vascular function and tumor angiogenesis. Blood 114, 469-477 (2009).

112. Skuli, N. et al. Endothelial HIF-2alpha regulates murine pathological angiogenesis and revascularization processes. J. Clin. Invest. 122, 1427-1443 (2012).

113. Tang, N. et al. Loss of HIF-1alpha in endothelial cells disrupts a hypoxia-driven VEGF autocrine loop necessary for tumorigenesis. Cancer Cell. 6, 485-495 (2004).

114. Du, R. et al. HIF1alpha induces the recruitment of bone marrow-derived vascular modulatory cells to regulate tumor angiogenesis and invasion. Cancer Cell. 13, 206-220 (2008). 
115. Fernandez-Alonso, R. et al. p73 is required for endothelial cell differentiation, migration and the formation of vascular networks regulating VEGF and TGFbeta signaling. Cell. Death. Differ. 22, 1287-1299 (2015).

116. Nauta, T. D. et al. Identification of HIF-2alpha-regulated genes that play a role in human microvascular endothelial sprouting during prolonged hypoxia in vitro. Angiogenesis 20, 39-54 (2017).

117. Hielscher, A., Qiu, C., Porterfield, J., Smith, Q. \& Gerecht, S. Hypoxia affects the structure of breast cancer cell-derived matrix to support angiogenic responses of endothelial cells. J. Carcinog. Mutagen. (Suppl 13), 005 (2013)

118. Wang, L. et al. Glycation of vitronectin inhibits VEGF-induced angiogenesis by uncoupling VEGF receptor-2-alphavbeta3 integrin cross-talk. Cell. Death Dis. 6 e1796 (2015)

119. Brurberg, K. G., Graff, B. A., Olsen, D. R. \& Rofstad, E. K. Tumor-line specific pO (2) fluctuations in human melanoma xenografts. Int. J. Radiat. Oncol. Biol. Phys. 58, 403-409 (2004).

120. Franses, J. W., Baker, A. B., Chitalia, V. C. \& Edelman, E. R. Stromal endothelial cells directly influence cancer progression. Sci. Transl. Med. 3, 66ra65 (2011).

121. Branco-Price, C. et al. Endothelial cell HIF-1alpha and HIF-2alpha differentially regulate metastatic success. Cancer Cell. 21, 52-65 (2012).

122. Sweeney, M. D., Ayyadurai, S. \& Zlokovic, B. V. Pericytes of the neurovascular unit: key functions and signaling pathways. Nat. Neurosci. 19, 771-783 (2016).

123. Kawakami, T., Mimura, I., Shoji, K., Tanaka, T. \& Nangaku, M. Hypoxia and fibrosis in chronic kidney disease: crossing at pericytes. Kidney Int. Suppl. 4, 107-112 (2014)

124. Mohammed, R. A., Ellis, I. O., Elsheikh, S., Paish, E. C. \& Martin, S. G. Lymphatic and angiogenic characteristics in breast cancer: morphometric analysis and prognostic implications. Breast Cancer Res. Treat. 113, 261-273 (2009).

125. Bos, R. et al. Levels of hypoxia-inducible factor-1alpha independently predict prognosis in patients with lymph node negative breast carcinoma. Cancer 97, 1573-1581 (2003)

126. Schoppmann, S. F. et al. Hypoxia inducible factor-1alpha correlates with VEGF-C expression and lymphangiogenesis in breast cancer. Breast Cancer Res. Treat. 99, 135-141 (2006).

127. Kurokawa, T. et al. Overexpression of hypoxia-inducible-factor 1alpha(HIF1alpha) in oesophageal squamous cell carcinoma correlates with lymph node metastasis and pathologic stage. Br. J. Cancer 89, 1042-1047 (2003).

128. Ji, R. C. Hypoxia and lymphangiogenesis in tumor microenvironment and metastasis. Cancer Lett. 346, 6-16 (2014).

129. Zampell, J. C. et al. HIF-1alpha coordinates lymphangiogenesis during wound healing and in response to inflammation. FASEB J. 26, 1027-1039 (2012).

130. Liang, $X$. et al. Hypoxia inducible factor-alpha expression correlates with vascular endothelial growth factor- $C$ expression and lymphangiogenesis/ angiogenesis in oral squamous cell carcinoma. Anticancer. Res. 28, 1659-1666 (2008)

131. min, Y. et al. C/EBP-delta regulates VEGF-C autocrine signaling in lymphangiogenesis and metastasis of lung cancer through HIF-1alpha. Oncogene 30, 4901-4909 (2011).

132. Morfoisse, F. et al. Hypoxia induces VEGF-C expression in metastatic tumor cells via a HIF-1alpha-independent translation-mediated mechanism. Cell. Rep. 6, 155-167 (2014).

133. Hirakawa, S. et al. VEGF-A induces tumor and sentinel lymph node lymphangiogenesis and promotes lymphatic metastasis. J. Exp. Med. 201, 1089-1099 (2005)

134. Geis, T. et al. HIF-2alpha attenuates lymphangiogenesis by up-regulating IGFBP1 in hepatocellular carcinoma. Biol. Cell. 107, 175-188 (2015).

135. Botta, C. et al. The route to solve the interplay between inflammation, angiogenesis and anti-cancer immune response. Cell. Death Dis. 7, e2299 (2016).

136. Triner, D. \& Shah, Y. M. Hypoxia-inducible factors: a central link between inflammation and cancer. J. Clin. Invest. 126, 3689-3698 (2016).

137. Sitkovsky, M. \& Lukashev, D. Regulation of immune cells by local-tissue oxygen tension: HIF1 alpha and adenosine receptors. Nat. Rev. Immunol. $\mathbf{5}$ 712-721 (2005)

138. Mamlouk, S. et al. Loss of prolyl hydroxylase-2 in myeloid cells and Tlymphocytes impairs tumor development. Int. J. Cancer 134, 849-858 (2014).

139. Bose, T., Cieslar-Pobuda, A. \& Wiechec, E. Role of ion channels in regulating $\mathrm{Ca}(2)(+)$ homeostasis during the interplay between immune and cancer cells. Cell. Death Dis. 6, e1648 (2015)

140. Yoshida, $\mathrm{N}$. et al. Anoxia/reoxygenation-induced neutrophil adherence to cultured endothelial cells. Am. J. Physiol. 262, H1891-1898 (1992).
141. Cramer, T. et al. HIF-1alpha is essential for myeloid cell-mediated inflammation. Cell 112, 645-657 (2003).

142. Thompson, A. A. et al. Hypoxia-inducible factor 2alpha regulates key neutrophil functions in humans, mice, and zebrafish. Blood 123, 366-376 (2014).

143. Walmsley, S. R. et al. Hypoxia-induced neutrophil survival is mediated by HIF1alpha-dependent NF-kappaB activity. J. Exp. Med. 201, 105-115 (2005).

144. Wendland, K., Thielke, M., Meisel, A. \& Mergenthaler, P. Intrinsic hypoxia sensitivity of the cytomegalovirus promoter. Cell. Death Dis. 6, e1905 (2015).

145. Mantovani, A., Cassatella, M. A., Costantini, C. \& Jaillon, S. Neutrophils in the activation and regulation of innate and adaptive immunity. Nat. Rev. Immunol. 11. 519-531 (2011).

146. Bingle, L., Brown, N. J. \& Lewis, C. E. The role of tumour-associated macrophages in tumour progression: implications for new anticancer therapies. J. Pathol. 196, 254-265 (2002)

147. Qian, B. Z. \& Pollard, J. W. Macrophage diversity enhances tumor progression and metastasis. Cell 141, 39-51 (2010).

148. Rolny, C. et al. HRG inhibits tumor growth and metastasis by inducing macrophage polarization and vessel normalization through downregulation of PIGF. Cancer Cell. 19, 31-44 (2011)

149. Casazza, A. et al. Impeding macrophage entry into hypoxic tumor areas by Sema3A/Nrp1 signaling blockade inhibits angiogenesis and restores antitumor immunity. Cancer Cell. 24, 695-709 (2013).

150. Matschurat, S. et al. Regulation of EMAP II by hypoxia. Am. J. Pathol. 162 93-103 (2003).

151. Murdoch, C., Giannoudis, A. \& Lewis, C. E. Mechanisms regulating the recruitment of macrophages into hypoxic areas of tumors and other ischemic tissues. Blood 104, 2224-2234 (2004).

152. Semba, H. et al. HIF-1alpha-PDK1 axis-induced active glycolysis plays an essential role in macrophage migratory capacity. Nat. Commun. 7, 11635 (2016)

153. Laoui, D. et al. Tumor hypoxia does not drive differentiation of tumorassociated macrophages but rather fine-tunes the M2-like macrophage population. Cancer Res. 74, 24-30 (2014).

154. Colegio, O. R. et al. Functional polarization of tumour-associated macrophages by tumour-derived lactic acid. Nature 513, 559-563 (2014).

155. Doedens, A. L. et al. Macrophage expression of hypoxia-inducible factor-1 alpha suppresses T-cell function and promotes tumor progression. Cancer Res. 70, 7465-7475 (2010)

156. Imtiyaz, H. Z. et al. Hypoxia-inducible factor 2alpha regulates macrophage function in mouse models of acute and tumor inflammation. J. Clin. Invest. 120, 2699-2714 (2010).

157. Gabrilovich, D. I. \& Nagaraj, S. Myeloid-derived suppressor cells as regulators of the immune system. Nat. Rev. Immunol. 9, 162-174 (2009).

158. Corzo, C. A. et al. HIF-1alpha regulates function and differentiation of myeloid-derived suppressor cells in the tumor microenvironment. J. Exp. Med. 207, 2439-2453 (2010).

159. Noman, M. Z. et al. Tumor-promoting effects of myeloid-derived suppressor cells are potentiated by hypoxia-induced expression of miR-210. Cancer Res. 75, 3771-3787 (2015).

160. Pastula, A. \& Marcinkiewicz, J. Myeloid-derived suppressor cells: a doubleedged sword? Int. J. Exp. Pathol. 92, 73-78 (2011).

161. Liu, G. et al. SIRT1 limits the function and fate of myeloid-derived suppressor cells in tumors by orchestrating HIF-1alpha-dependent glycolysis. Cancer Res. 74, 727-737 (2014)

162. Le, Q. T. et al. Galectin-1: a link between tumor hypoxia and tumor immune privilege. J. Clin. Oncol. 23, 8932-8941 (2005)

163. Chang, C. H. et al. Metabolic competition in the tumor microenvironment is a driver of cancer progression. Cell 162, 1229-1241 (2015)

164. Ho, P. C. et al. Phosphoenolpyruvate is a metabolic checkpoint of anti-tumor T cell responses. Cell 162, 1217-1228 (2015).

165. Lee, H. J. et al. Glycerol-3-phosphate acyltransferase-1 upregulation by $\mathrm{O}$ GlcNAcylation of Sp1 protects against hypoxia-induced mouse embryonic stem cell apoptosis via mTOR activation. Cell. Death Dis. 7, e2158 (2016)

166. Ben-Shoshan, J., Maysel-Auslender, S., Mor, A., Keren, G. \& George, J. Hypoxia controls CD4+CD25+regulatory T-cell homeostasis via hypoxia-inducible factor-1alpha. Eur. J. Immunol. 38, 2412-2418 (2008)

167. Clambey, E. T. et al. Hypoxia-inducible factor-1 alpha-dependent induction of FoxP3 drives regulatory T-cell abundance and function during inflammatory hypoxia of the mucosa. Proc. Natl. Acad. Sci. USA 109, E2784-2793 (2012).

168. Dang, E. V. et al. Control of $\mathrm{T}(\mathrm{H}) 17 / \mathrm{T}(\mathrm{reg})$ balance by hypoxia-inducible factor 1. Cell 146, 772-784 (2011). 
169. Bailey, S. R. et al. Th17 cells in cancer: the ultimate identity crisis. Front. Immunol. 5, 276 (2014).

170. Facciabene, A. et al. Tumour hypoxia promotes tolerance and angiogenesis via CCL28 and T(reg) cells. Nature 475, 226-230 (2011).

171. Viguier, M. et al. Foxp3 expressing CD4 + CD25(high) regulatory $T$ cells are overrepresented in human metastatic melanoma lymph nodes and inhibit the function of infiltrating T cells. J. Immunol. 173, 1444-1453 (2004).

172. Zhao, X. et al. A novel differentiation pathway from CD4(+) T cells to CD4(-) T cells for maintaining immune system homeostasis. Cell. Death Dis. 7, e2193 (2016).

173. Ohta, A. et al. A2A adenosine receptor protects tumors from antitumor T cells. Proc. Natl. Acad. Sci. USA 103, 13132-13137 (2006).

174. Synnestvedt, K. et al. Ecto-5'-nucleotidase (CD73) regulation by hypoxiainducible factor-1 mediates permeability changes in intestinal epithelia. J. Clin. Invest. 110, 993-1002 (2002).

175. Cox, T. R. et al. The hypoxic cancer secretome induces pre-metastatic bone lesions through lysyl oxidase. Nature 522, 106-110 (2015).

176. Sceneay, J. et al. Primary tumor hypoxia recruits CD11b+/Ly6Cmed/Ly6G+ immune suppressor cells and compromises NK cell cytotoxicity in the premetastatic niche. Cancer Res. 72, 3906-3911 (2012).

177. Barsoum, I. B., Smallwood, C. A., Siemens, D. R. \& Graham, C. H. A mechanism of hypoxia-mediated escape from adaptive immunity in cancer cells. Cancer Res. 74, 665-674 (2014).

178. Noman, M. Z. et al. PD-L1 is a novel direct target of HIF-1alpha, and its blockade under hypoxia enhanced MDSC-mediated T cell activation. J. Exp. Med. 211, 781-790 (2014).

179. Wang, S. C. et al. PD-1 and Tim-3 pathways are associated with regulatory CD8+ T-cell function in decidua and maintenance of normal pregnancy. Cell. Death Dis. 6, e1738 (2015).

180. Chinai, J. M. et al. New immunotherapies targeting the PD-1 pathway. Trends Pharmacol. Sci. 36, 587-595 (2015).

181. Yamazaki, T. et al. The oncolytic peptide LTX-315 overcomes resistance of cancers to immunotherapy with CTLA4 checkpoint blockade. Cell. Death. Differ. 23, 1004-1015 (2016)

182. Doedens, A. L. et al. Hypoxia-inducible factors enhance the effector responses of CD8(+) $T$ cells to persistent antigen. Nat. Immunol. 14 1173-1182 (2013).

183. Topalian, S. L., Taube, J. M., Anders, R. A. \& Pardoll, D. M. Mechanism-driven biomarkers to guide immune checkpoint blockade in cancer therapy. Nat. Rev. Cancer 16, 275-287 (2016).

184. Ott, P. A., Hodi, F. S. \& Robert, C. CTLA-4 and PD-1/PD-L1 blockade: new immunotherapeutic modalities with durable clinical benefit in melanoma patients. Clin. Cancer Res. 19, 5300-5309 (2013).

185. Shaabani, N. et al. CD169+ macrophages regulate PD-L1 expression via type I interferon and thereby prevent severe immunopathology after LCMV infection. Cell. Death Dis. 7, e2446 (2016).

186. Wolchok, J. D. \& Chan, T. A. Cancer: antitumour immunity gets a boost. Nature 515, 496-498 (2014).

187. Dominguez, C., Tsang, K. Y. \& Palena, C. Short-term EGFR blockade enhances immune-mediated cytotoxicity of EGFR mutant lung cancer cells: rationale for combination therapies. Cell. Death Dis. 7, e2380 (2016).

188. Ottensmeier, C. H. et al. Upregulated glucose metabolism correlates inversely with CD8+T-cell infiltration and survival in squamous cell carcinoma. Cancer Res. 76, 4136-4148 (2016).

189. Tyrakis, P. A. et al. S-2-hydroxyglutarate regulates CD8+ T-lymphocyte fate. Nature 540, 236-241 (2016).

190. Velasquez, S. Y. et al. Short term hypoxia synergizes with interleukin 15 priming in driving glycolytic gene transcription and supports human natural killer cell activities. J. Biol. Chem. 291, 12960-12977 (2016).
191. Filatova, A. et al. Acidosis acts through HSP9O in a PHDNHL-Independent manner to promote HIF function and stem cell maintenance in glioma. Cancer Res. 76, 5845-5856 (2016).

192. Lu, H., Forbes, R. A. \& Verma, A. Hypoxia-inducible factor 1 activation by aerobic glycolysis implicates the Warburg effect in carcinogenesis. J. Biol. Chem. 277, 23111-23115 (2002).

193. Mekhail, K., Gunaratnam, L., Bonicalzi, M. E. \& Lee, S. HIF activation by pHdependent nucleolar sequestration of VHL. Nat. Cell. Biol. 6, 642-647 (2004).

194. Koh, M. Y., Lemos, R. Jr, Liu, X. \& Powis, G. The hypoxia-associated factor switches cells from HIF-1alpha- to HIF-2alpha-dependent signaling promoting stem cell characteristics, aggressive tumor growth and invasion. Cancer Res. 71, 4015-4027 (2011)

195. Amelio, I. \& Melino, G. The p53 family and the hypoxia-inducible factors (HIFs): determinants of cancer progression. Trends Biochem. Sci. 40, 425-434 (2015).

196. Charni, M., Aloni-Grinstein, R., Molchadsky, A. \& Rotter, V. p53 on the crossroad between regeneration and cancer. Cell. Death. Differ. 24, 8-14 (2017).

197. Belle, J. I. et al. Repression of p53-target gene Bbc3/PUMA by MYSM1 is essential for the survival of hematopoietic multipotent progenitors and contributes to stem cell maintenance. Cell. Death. Differ. 23, 759-775 (2016).

198. Charni, M. et al. Novel p53 target genes secreted by the liver are involved in non-cell-autonomous regulation. Cell. Death. Differ. 23, 509-520 (2016).

199. Desantis, A. et al. Che-1 modulates the decision between cell cycle arrest and apoptosis by its binding top53. Cell. Death Dis. 6, e1764 (2015)

200. Kruiswijk, F., Labuschagne, C. F. \& Vousden, K. H. p53 in survival, death and metabolic health: a lifeguard with a licence to kill. Nat. Rev. Mol. Cell. Biol. 16 393-405 (2015).

201. Rufini, A. et al. p73 in Cancer. Genes. \& Cancer 2, 491-502 (2011)

202. Agostini M. et al. (2017). p73 Regulates primary cortical neuron metabolism: a global metabolic profile. Mol. Neurobiol.

203. Amelio, I. et al. TAp73 promotes anabolism. Oncotarget 5, 12820-12934 (2014).

204. Amelio, I., Cutruzzola, F., Antonov, A., Agostini, M. \& Melino, G. Serine and glycine metabolism in cancer. Trends Biochem. Sci. 39, 191-198 (2014).

205. Amelio, I. et al. p73 regulates serine biosynthesis in cancer. Oncogene $\mathbf{3 3}$ 5039-5046 (2014).

206. Candi, E. et al. Metabolic pathways regulated by p63. Biochem. Biophys. Res. Commun. 482, 440-444 (2017).

207. Yang, M. \& Vousden, K. H. Serine and one-carbon metabolism in cancer. Nat. Rev. Cancer 16, 650-662 (2016).

208. Inoue, S. et al. TAp73 is required for spermatogenesis and the maintenance of male fertility. Proc. Natl. Acad. Sci. USA 111, 1843-1848 (2014).

209. Levine, A. J., Tomasini, R., McKeon, F. D., Mak, T. W. \& Melino, G. The p53 family: guardians of maternal reproduction. Nat. Rev. Mol. Cell. Biol. 12 259-265 (2011)

210. Candi, E., Amelio, I., Agostini, M. \& Melino, G. MicroRNAs and p63 in epithelial stemness. Cell. Death. Differ. 22, 12-21 (2015).

211. Lena, A. M. et al. Skn-1a/Oct-11 and DeltaNp63alpha exert antagonizing effects on human keratin expression. Biochem. Biophys. Res. Commun. 401, 568-573 (2010)

212. Niklison-Chirou, M. V. et al. How Does p73 Cause Neuronal Defects? Mol Neurobiol. 53, 4509-4520 (2016).

213. Vanbokhoven, H., Melino, G., Candi, E. \& Declercq, W. p63, a story of mice and men. J. Invest. Dermatol. 131, 1196-1207 (2011).

214. Semenza, G. L. Targeting HIF-1 for cancer therapy. Nat. Rev. Cancer 3, 721-732 (2003). 